Supplement of Geosci. Model Dev., 8, 3055-3070, 2015

http://www.geosci-model-dev.net/8/3055/2015/

doi:10.5194/gmd-8-3055-2015-supplement

(C) Author(s) 2015. CC Attribution 3.0 License.

(c) (i)

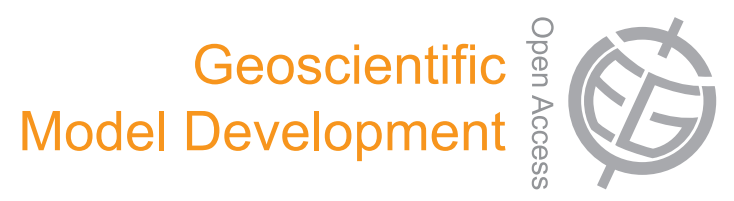

Supplement of

\title{
A soil diffusion-reaction model for surface COS flux: COSSM v1
}

W. Sun et al.

Correspondence to: W. Sun (wu.sun@ucla.edu) and U. Seibt (useibt@ucla.edu)

The copyright of individual parts of the supplement might differ from the CC-BY 3.0 licence. 
To demonstrate quantitatively that aqueous diffusive flux is small compared to gaseous diffusive flux, we assume a soil column of vertically uniform profiles of porosity, temperature and moisture,

$$
\begin{aligned}
\theta_{\text {sat }} & =0.50 \mathrm{~m}^{3} \mathrm{~m}^{-3} \\
T & =25^{\circ} \mathrm{C} \\
\theta_{\mathrm{w}} & =0.25 \mathrm{~m}^{3} \mathrm{~m}^{-3}
\end{aligned}
$$

The factor $b$ in Eq. (13) in the main text is set to 5.3 here, without losing generality. The soil gaseous diffusivity for COS calculated based on Eq. (13) in the main text is, $D_{\mathrm{g}}=5.64 \times 10^{-7} \mathrm{~m}^{2} \mathrm{~s}^{-1}$. The molecular aqueous diffusivity for COS calculated from Ulshöfer et al. (1996) is $D_{\mathrm{m}, \mathrm{aq}}=1.94 \times 10^{-9} \mathrm{~m}^{2} \mathrm{~s}^{-1}$. Then by counting the tortuosity effect using Eq. (3) in Moldrup et al. (2003), we obtain the actual soil aqueous diffusivity for $\operatorname{COS}, D_{\text {aq }}=7.13 \times$ $10^{-11} \mathrm{~m}^{2} \mathrm{~s}^{-1}$.

We consider the steady-state COS flux of the soil (i.e. $\partial C / \partial t=0$ ) with a sink proportional to the concentration and no production term. We obtain the equation,

$D \frac{\mathrm{d}^{2} C}{\mathrm{~d} z^{2}}=-S=k C$

with the boundary condition $C(z=0)=C_{\text {atm }}$. We obtain the general solution,

$C(z)=C_{\text {atm }} \exp (-\sqrt{k / D} \cdot z)$

The surface flux is thus

$F=-\left.D \frac{\mathrm{d} C}{\mathrm{~d} z}\right|_{z=0}=\sqrt{k D} C_{\text {atm }}$

which is proportional to $\sqrt{D}$. We can then calculate the ratio of aqueous diffusive flux $\left(F_{\mathrm{aq}}\right)$ to gaseous diffusive flux $\left(F_{\mathrm{g}}\right)$,

$\frac{F_{\mathrm{aq}}}{F_{\mathrm{g}}}=\sqrt{\frac{D_{\mathrm{aq}}}{D_{\mathrm{g}}}}=0.0112$

Under most conditions, the aqueous diffusive flux is a small fraction of the total flux (Fig. S1). Hence, any errors from neglecting aqueous diffusion are usually small $(<10 \%$ at water filled pore space below $83 \%$ ), except at high soil moisture when the overall flux also tends to be small (see Fig. 9).

\section{References}

Moldrup, P., Olesen, T., Komatsu, T., Yoshikawa, S., Schjønning, P., and Rolston, D.: Modeling diffusion and reaction in soils: X. A unifying model for solute and gas diffusivity in unsaturated soil, Soil Science, 168, 321-337, 2003.

Ulshöfer, V., Flock, O., Uher, G., and Andreae, M.: Photochemical production and air-sea exchange of carbonyl sulfide in the eastern Mediterranean Sea, Marine Chemistry, 53, 25-39, doi 10.1016/0304-4203(96)00010-2. 1996.

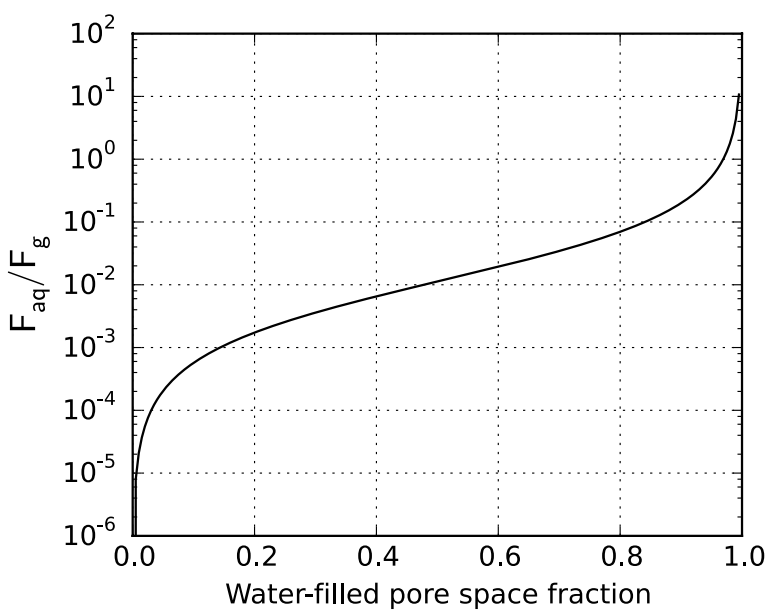

Figure S1. The ratio of aqueous flux to gaseous flux for an ideal case with soil porosity $0.50 \mathrm{~m}^{3} \mathrm{~m}^{-3}$. COS uptake velocity is assumed constant. 